\title{
Configurações corporais no espaço heterotópico da cidade em Lãs ao vento, de Arriete Vilela
}

\section{ELAINE RAPÔSO}

: Bolsista da Fundação de Amparo à Pesquisa em

:Alagoas (FAPEAL), integrante do Grupo Mare\&sal

:Estudos e Pesquisas Interdiscaplinares. Mestranda do

:Programa de Pós-Graduaçāo em Letras e Lingüística da

: Universidade Federal de Alagoas. Sob a orientaçāo da

: profa. Dra. Izabel Brandāo, desenvolve dissertaçāo sobre

:o romanœ analisado neste artigo.

: Resumo: A partir da leitura de Lãs ao vento, de :Arriete Vilela, e ancorado nas idèias de Foucault e :Grosz, este artigo centra seu olhar em construçōes :corporais no espaço urbano, pensado aqui em suas :configuraçōes heterotópicas conforme nos permite : pensar a óptica foucaultiana. O objetivo é visualizar : na interação corpo-espaço, construçōes :socioculturais que nāo só incidem sobre o corpo dos :meninos de rua, mas que são também construídas : a partir de seus corpos, operando sua reificação.

: Palavras-chave: Arriete Vilela; cidade; corpo; gênero; heterotopias
Abstract. Based on Foucault and Grosz's ideas, this article presents an analysis of Lãs ao vento, by Arriete Vilela, focusing the corporal constructs in the urban space, which is here understood in terms of its Foucaultian heterotopic configuration. My aim is to visualize, within the scope of the body-space interaction, the social-cultural constructs, which by reflecting upon streetboys' bodies, reify them.

Key words: Arriete Vilela; city; body; gender; heterotopia 

Observar o modo como a questão da cidade é filtrada literariamente por Arriete Vilela, em Lãs ao vento, ${ }^{1}$ pode ser considerado uma porta de entrada válida para a discussão das construções/representações corporais no espaço urbano, cuja configuração encontra um paralelo na estrutura dessa obra, principalmente, quando pensamos na fragmentação e na multiplicidade da cidade, "[...] o lugar por excelência da heterogeneidade [...]" (GIASSONE, 1999, p. 30). Afinal, qual lance de olhar conseguiria abarcar a visão da cidade em sua totalidade? Que golpe de vista possibilitaria plasmar as múltiplas experiências que o espaço urbano oferece a cada segundo? A visão que temos da cidade, longe de querer pensá-la em seu todo, cheganos a partir de fragmentos/recortes que nos são dados a cada esquina; e, se justapusermos os fragmentos como num quebra-cabeça, veremos sempre que nos faltam peças, que algo nos escapa... Enfim, teremos a certeza de que ela não se dá a apreender em seu todo.

Essa fragmentação e heterogeneidade características do espaço urbano dão a tônica da estrutura dessa obra, "escritura de esfacelamentos, de recortes da realidade, de bordejos e desesperanças” (VILELA, 2005, p.2). De um romance, temos apenas o traço inicial, gradativamente esgarçado pela convivência conflituosa, no mesmo espaço literário, de formas "narrativas" diversas que se imiscu$\mathrm{em}^{2}$ : intercalam-se cartas à Senhora Editora, pequenas narrativas e memórias. O que percebemos, então, é que a experiência da hibridização, acentuada no espaço urbano, reflete-se na obra através da convivência sempre tensa entre o canônico e o não-canônico, o erudito e o popular, o rural (através das lendas/histórias de base oral) e o urbano que nos chega através das histórias doídas das crianças de rua. Lendas e histórias do meio rural convivem, no mesmo espaço literário, com boletins de ocorrência que denunciam as dores das crianças de rua, chamadas de "pardaizinhos" pela narradora. O travo herdado da palavra de João Hercílio, avô da narradora-personagem, é a principal característica não só dessas narrativas como também dos espaços que as compõem. Chegam-nos, então,
'Uma versão deste trabalho foi apresentada no II Colóquio Nacional de Representações de Gênero e Sexualidades, realizado na Universidade Estadual da Paraíba (2006) e publicada nos anais do evento. As citações à obra encontram-se em: VILELA, Arriete. Lãs ao vento. Rio de Janeiro: Gryphus, 2005.

${ }^{2} \mathrm{~A}$ visão do híbrido, pensado como o que é positivamente impuro, segundo a óptica de Canclini (1998), pode fornecer elementos para a compreensão dos (des)contornos desse texto arrieteano. Uma análise nesse sentido está sendo desenvolvida como parte integrante da pesquisa em andamento que, em fase de finalização, é desenvolvida no PPGLL/UFAL. 
${ }^{3}$ Bachelard, em $L a$ poétique de l'espace, de 1958, no capítulo LX, apresenta uma percepção que permite pensar o interior e o exterior como espaços em constante fluxo, constituindo-se como lugares de intimidade. A visão de Candido (1985), posterior à teorização de Bachelard, aponta a possibilidade de visualizar esse movimento dialético como um componente do texto literário, mostrando o modo como componentes internos $\mathrm{e}$ externos à obra participam mutuamente do processo de construção literária. (Nesse trabalho, foi utilizada uma edição traduzida do texto de Bachelard, v. referência). crianças das "[...] nas ruas, literalmente. Ao relento. Em farrapos. Exploradas, maltratadas, humilhadas, excluídas". (VILELA, 2005, p. 12).

Embora o meio rural tenha um lugar extremamente significativo no texto arrieteano, o olhar da narradora que o constitui é urbano, trazendo para dentro da obra a heterogeneidade e o hibridismo próprios da cidade. O que vemos, então, são fatores externos - o hibridismo e a heterogeneidade que caracterizam a cidade - tornaremse elementos constitutivos dessa obra, dando-lhe corpo e estrutura, permitindo-nos ver o modo como se operacionaliza aqui o princípio da redução estrutural, de Antonio Candido (1993, p. 9), definido pelo crítico como "o processo por cujo intermédio a realidade do mundo e do ser se torna, na narrativa ficcional, componente de uma estrutura literária [...]". O modo como elementos externos e internos dialogam no texto literário pode ser melhor entendido quando pensamos o movimento dialético entre o interior e o exterior, segundo a óptica de Bachelard ${ }^{3}$ (1989), quando ele os apresenta como espaços em constante fluxo. Pensar o interior e o exterior segundo o ponto de vista bachelardiano possibilita-nos, inclusive, uma maior compreensão de Candido, quando este afirma que "[...] o externo se torna interno [...]". (CANDIDO, 1985, p. 6; grifos do autor)

Os recortes que compõem a obra - lendas de base oral, narrativas do meio urbano, boletins "oficiais", memórias e confissões - são, entretanto, amarrados pelas cartas à Senhora Editora. Através delas são-nos lançados fios que nos atam às figuras de Theonila Cândida, João Hercílio e D. Anna Joaquina, conduzindo-nos ora às narrativas / lendas da tradição oral, ora nos trazendo literariamente a dura realidade das crianças de rua, fazendo-nos transitar entre os meios rural e o urbano. Essas cartas exercem ainda, a nosso ver, duas outras funções importantes nesse texto:

1) trazem à nossa memória, como já salienta Brandão (2005, p. 5), uma prática recorrente entre mulheres: quando lhes cabia apenas o espa- 
ço privado, "[...] mulheres escreviam cartas por não poderem se expressar de outra forma [...]"; 2) mostram, não só a profissionalização da literatura, mas também a profissionalização da mulher escritora, que agora pode ocupar espaços públicos.

Assim, num primeiro momento, essas cartas recuperam um traço da história das mulheres escritoras. Quando impossibilitadas de ocupar espaços públicos, algumas mulheres recorriam à escrita de cartas para burlar o cerco que lhes era socialmente imposto. Através da pena de Arriete Vilela, esse dado histórico é re-significado. Agora, essa prática passa pelo crivo da profissionalização da literatura e da mulher escritora, o que pode ser percebido quando atentamos para o fato de que a personagem-narradora-escritora envia correspondências para a sua editora, dando conta dos progressos e entraves no processo de escrita de seu livro, denotando a instauração de uma relação profissional entre ambas.

Além disso, o transitar entre tantas narrativas/espaços, conduzido pelas cartas, leva-nos a pensá-las associadas ao processo de descentralização, conforme apresentado por Hutcheon (1991, p. 84-103), como uma das principais características da pós-modernidade. Tal perspectiva é pertinente também para pensar a própria crítica feminista e o modo como ela se insere nesse contexto. Esta pode ser lida, dentre outras possibilidades, como a determinação de um espaço no qual narrativas de autoria feminina possuem um "trânsito livre". A demarcação política desse território pode ser entendida, de acordo com o dizer de Bellei (2000, p. 160), como "[...] um não-lugar em que não se está nem dentro [...] [do cânone, da cultura central] e nem fora (da cultura periférica [do espaço marginal])". Tal área de atuação - com o seu próprio centro e as suas próprias margens - pode ser vista, então, como um dos picadeiros do "[...] circo com vários picadeiros [que] passa a ser a metáfora pluralizada e paradoxal para um mundo descentralizado onde só existe ex-centricidade" (HUTCHEON, 1991, p. 89). Metáfora paradoxal, sim, principalmente se pen- 
sarmos que, na verdade, cada "picadeiro" neste "circo" constitui um centro - ainda que de ex-cêntricos. É justamente a existência de tantos centros - seria melhor dizer de tantos ex-cêntricos? - que nos leva a (re)pensar a questão das margens, não só relacionada aos espaços socioculturalmente representados nesta obra, mas também às formas de lidar com os corpos aí representados.

Os espaços que as crianças de Lãs ao vento habitam estão diretamente ligados a suas condições marginais. Tanto nas narrativas que se voltam para o meio rural e que são motivadas por ele, quanto nas que nos chegam pelo fio puxado por D. Anna Joaquina, trazendo crianças do espaço urbano, podemos visualizar essa condição marginal: a margem, o "off-centro", é o seu espaço. A metáfora dos picadeiros, conforme apresentada por Hutcheon, pode ajudar a compreender melhor a condição das crianças apresentadas nesta obra, principalmente quando pensamos nas crianças de rua: seus grupos também são centros de ex-cêntricos. Pode-se, ainda, aplicá-la à observação da estrutura desse texto: cada pequena narrativa é um "picadeiro" com um espaço e um eixo próprio que contesta a centralização narrativa - não há, aqui, uma trama unificada - ampliando a zona de contato entre o imaginário e o realista (cf. HUTCHEON, 1991, p. 89). Por isso, temos, nesse caso, uma forma híbrida na qual convivem tensamente, dividindo o mesmo "território", cartas, lendas, histórias de meninos e meninas de rua e boletins "oficiais".

Além de propiciar a descentralização narrativa, tal processo, com seu desafio às noções de centro, de totalidade e de universalidade, é, ainda no dizer de Hutcheon (1991), a principal característica de nossos tempos. Como conseqüência, vemos ruir as bases que, durante muito tempo, sustentaram uma cultura e um pensamento fundamentados em pares dicotômicos que, dentre outras formas de manifestação, apresentam homens e mulheres como seres constituídos por mente e corpo: par oposto, no qual a mente é valorizada em detrimento do corpo.

Trazer essa questão para o centro das discussões de gênero é pertinente porque percebemos, com 
Grosz (2000, p. 45-86), que tal oposição - mente x corpo - encontra seu correlato na oposição homem e mulher. Nesse caso, ela - a mulher - é associada ao corpo / às funções biológicas, sendo desprivilegiada em favorecimento do homem, tido como superior, já que é visto como um correlato para a mente. Ainda concordando com Grosz (2000, p. 45), acreditamos que trazer questões relacionadas ao corpo para o centro das discussões de gênero é uma forma de desafiar construções arraigadas em nossa cultura, já que "se a teoria feminista aceita acriticamente essas suposições comuns, ela participa da desvalorização social do corpo que anda de mãos dadas com a opressão das mulheres". É pertinente, então, observar o modo como a teoria/crítica feminista tem avançado nessas questões, tomando o corpo como uma categoria de análise útil contra a opressão das mulheres.

Importa ressaltar que a categoria de gênero é utilizada neste artigo numa perspectiva que não se restringe à consideração de questões relacionadas exclusivamente ao ser ou à experiência das mulheres. Vale, pois, neste momento, concordando com o pensamento de Barbieri, observar que a categoria de gênero "[...] demanda dar espaço à busca de sentido do comportamento de homens e mulheres como seres socialmente sexuados" (BARBIERI, 1993, p. 5), não esquecendo o fato de que, ainda segundo Barbieri, essa categoria pode ser pensada como constitutiva de um sistema de poder. Assim os relacionamentos/comportamentos de homens e mulheres, enquanto "seres socialmente sexuados", têm de ser pensados levando-se em conta as lutas por poder e significado que se desenvolvem a partir desse sistema. Nessa perspectiva, a categoria de gênero pode ser utilizada também para considerar os relacionamentos/comportamentos das personagens de Lãs ao vento, no que se refere aqui aos meninos de rua representados nessa obra, bem como aos adultos que com eles se relacionam. A partir da consideração desses relacionamentos, podemos entender como se dão as construções corporais dessas crianças, considerando, para isso, o espaço da rua que elas ocupam. 
${ }^{4}$ Pensando

antropologicamente a questão do espaço, Augé (1994) mostra que este se constitui como um lugar a partir do momento em que lhe são atribuídos significados/valores e ele se torna relacional, histórico e identitário. Nesse sentido, podemos pensar o espaço da rua como um lugar, a partir do momento em que ele participa como um elemento importante na constituição de uma identidade urbana, coletiva. No entanto, por ser um espaço de trânsito, não exerce a mesma função na constituição de uma identidade pessoal do sujeito.
Considerar, pois, o espaço das ruas ocupado pelos "pardaizinhos" é de fundamental importância para a compreensão de suas configurações corporais, principalmente quando, adotando a perspectiva apresentada por Foucault (2001, p. 411-422), pensamos a questão espacial em termos não de localização, mas de posicionamento. Segundo sua óptica, estamos em um momento em que o mundo se experimenta "[...] como uma rede que liga pontos e entrecruza a sua trama" (FOUCAULT, 2001, p. 411). $\mathrm{O}$ filósofo enfatiza que "[...] vivemos no interior de um conjunto de relações que definem posicionamentos [...]" (ibidem, p. 414). Pensar o espaço urbano no qual essas crianças se inserem a partir da perspectiva foucaultiana exige que voltemos nossa atenção para os posicionamentos, as redes de relações que elas aí estabelecem. Dessa forma, a questão do espaço não se restringe a considerações meramente geográficas, já que para Foucault (2001, p. 413), "estamos em uma época em que o espaço se oferece a nós sob a forma de relações de posicionamentos". Isso torna possível visualizar a relação existente entre o espaço que essas personagens ocupam e o modo como seus corpos são lidos/construídos.

Assim, o prisma pelo qual o espaço em que transitam essas personagens está sendo abordado ultrapassa o dado geográfico, sem, contudo, ignorá-lo: viver na rua é habitar a margem, é estar no "off-centro". A compreensão disso é fulcral para o entendimento do modo como se dão as construções corporais das crianças apresentadas no texto arrieteano.

Os grupos formados por elas, bem como o espaço no qual vivem podem ser entendidos como heterotopias. Opondo-se à irrealidade da utopia, as heterotopias são lugares reais, " $[\ldots]$ lugares que estão fora de zodos os lugares, embora sejam efetivamente localizáveis" (FOUCAULT, 2001, p. 415). Mesmo sendo claramente localizável, o espaço da rua que essas crianças ocupam, bem como os grupos que elas constituem não são considerados lugares ${ }^{4}$ social- $^{-}$ mente aceitos. Vistos apenas em termos periféricos, estão excluídos do centro sociocultural, ou seja, estão fora de 
todos os lugares/instituições sociais. É tendo em mente essas questões que podemos pensar esses grupos/espaços em termos heterotópicos.

Segundo Foucault (2001, p. 420), as heterotopias "[...] supõem sempre um sistema de abertura e fechamento que, simultaneamente, as isola e as torna penetráveis". Tal sistema de abertura e fechamento é importante para entender a constituição do grupo de meninos viciados em cola, formado por Algodão, seus três irmãos e outras crianças. $O$ fato de um menino/a de rua penetrar num desses grupos acentua a exclusão dessas crianças. Assim, almejase chegar a um lugar central - "Algodão era o líder de um grupo de viciados em cola de sapateiro [...]" (VILELA, 2005, p. 103) - mas só se chega às margens. O posicionamento particular de Algodão no grupo torna ainda mais visível o caráter heterotópico desse tipo de associação: "[...] ele mesmo nunca se drogava” (idem, p.103). Algodão não estava interessado no vício, o grupo se apresenta para ele como abertura para uma experiência de vida em coletividade, mas representa o fechamento em relação à vida no espaço central da sociedade.

É possível pensar esses grupos em termos de heterotopias de desvio, entendendo-as como o espaço dos "[...] indivíduos cujo comportamento desvia em relação à média ou à norma exigida" (FOUCAULT, 2001, p. 416), como acontece - guardadas as devidas ressalvas - nos hospitais e prisões. Os habitantes do espaço da rua não possuem um lugar aceito no âmbito da sociedade e de diversas formas o comportamento das crianças que habitam esse espaço desvia dos padrões de comportamento socialmente pré-estabelecidos. Aliás, o próprio fato de habitar o espaço da rua já constitui uma forma de desvio da norma, já que a rua é um espaço de trânsito e não se destina à permanência/ moradia de pessoas. As formas como essas crianças são vistas e tratadas é, de certa forma, determinada pelo espaço no qual elas estão inseridas e os abusos que elas sofrem podem ser entendidos como cruéis conseqüências dessa dura realidade.

Outras formas de heterotopia aparecem, ainda, 
${ }^{5} \mathrm{Em}$ "A história do corpo", Porter (1992) mostra que os componentes clássicos e os judaico-cristãos de nossa herança cultural fundamentaram uma visão dualista do ser humano, na qual mente e corpo aparecem como termos opostos, sendo o primeiro elemento valorizado em detrimento do segundo. Assim, o corpo representa o pólo negativo dessa dicotomia e o autor evidencia que o processo de desvalorização deste relega-o às margens dos ramos mais prestigiosos do saber. relacionadas às crianças que vivem sozinhas na rua. Em uma das linhas narrativas que compõem o romance, cujo personagem principal é Cocada, o carro do motorista com o qual o menino tem relações sexuais assume a função de motel, apresentando-se também como um espaço heterotópico, no qual "Cocada fazia sexo oral no motorista, protegido, ambos, pelas películas escuras do carro" (VILELA, 2005, p. 174). Na leitura que propomos, o carro aparece como um espaço heterotópico "[...] onde a sexualidade ilegal se encontra ao mesmo tempo absolutamente abrigada e absolutamente escondida, mantida afastada, sem ser, no entanto, inteiramente deixada ao ar livre" (FOUCAULT, 2001, p. 420). Essa heterotopia de desvio configura-se, nesse caso, como um espaço de transgressão no qual o cerco social é rompido e a sexualidade proibida é exercida livremente.

O espaço da cidade configura-se nessa obra como uma heterotopia quando o entendemos, pensando nas crianças que o habitam, como um "sistema de fechamento e abertura" (idem, p.420). Nos grupos dos quais participam, essas crianças assumem determinados posicionamentos centrais - pensamos aqui nas posições que elas ocupam, bem como na rede de relações que constituem - que as empurram, no entanto, para posições/espaços marginais: a entrada dos meninos nesses grupos acentua ainda mais a sua exclusão social, pois, “[...] acredita-se penetrar e se é, pelo próprio fato de entrar, excluído" (idem, loc. cit.). As heterotopias estão diretamente relacionadas às posições marginais que essas personagens de Lãs ao vento ocupam, sendo de suma importância entendê-las, se quisermos compreender o modo como seus corpos configuram-se.

Considerar as construções/configurações corporais dessas personagens inseridas nesses espaços exige que não nos esqueçamos - vale enfatizar - de que a forma como a nossa cultura, de um modo geral, lida com o corpo relegao ao espaço da margem. ${ }^{5}$ Dessa forma, este é apresentado como a parte negativa em pares dicotômicos como os que sugerem a oposição mente x corpo, alma x corpo (cf. GROSZ, 2000: 47-51). O pensamento dicotômico que está na 
base de nossa tradição cultural é responsável pela desvalorização do corpo e de tudo o que representa a base material de nossa cultura. Dessa forma, o corpo é apresentado como a parte negativa em pares como os que sugerem a oposição mente x corpo, alma x corpo. ${ }^{6} \mathrm{O}$ que Grosz evidencia, ao referir-se a essa divisão, é que ela não é neutra e possui associações laterais que desembocam em outras dicotomias como a que sugere a oposição natureza $\mathrm{x}$ cultura, fazendo com que esta seja valorizada em detrimento daquela. Assim, os termos que nesses pares representam a base material tornam-se partes suprimidas, desvalorizadas nos mais variados contextos.

É importante ressaltar, como destaca Porter (1992, p. 293), que essas "[...] velhas hierarquias culturais que privilegiaram a mente sobre o corpo [...] sancionaram sistemas inteiros de poder regulador-regulado" e podemos incluir as crianças nesse contexto. Como dissemos anteriormente, a oposição mente x corpo é correlata à oposição cultura x natureza. Se pensarmos o lugar tradicional da criança na sociedade veremos instaurar-se um novo par dicotômico, representado pela oposição criança x adulto/ a, lembrando que este/a é considerado/a como pertencente ao domínio da cultura e da mente e a criança como mais próxima da natureza e do corpo. Assim, "[...] postula-se a fragilidade natural da criança de acordo com sua situação biológica em formação; [...] é, pois, a natureza o âmbito preferencial da criança; não apenas seu habitat mais adequado, como aquele que abriga o modo mesmo como a infância é concebida". (ZILBERMAN, 2003, p. 19) Nesse contexto, devemos ter em mente o sistema de poder regulador-regulado do qual fala Porter, bem como suas associações laterais, para entender melhor o modo como esse novo par dicotômico se instaura e os posicionamentos que as crianças de Lãs ao ventoocupam, bem como o modo como alguns adultos se relacionam com elas.

Aproximando-nos mais das personagens dessa obra, poderemos observar como se concretizam as configurações de seus corpos como objetos de prazer, bem como as relações de poder que se estabelecem a partir de tais
${ }^{6}$ Cf. Grosz, 2000, p. 47-51. 
construções. Vemos desfilar, nessas narrativas, corpos duplamente reificados, tratados como mero objeto pelas ciências naturais, ou como objetos de prazer para o outro. Teoricamente, essa questão é abordada por Grosz (2000) num trabalho no qual, ao apresentar três linhas de pesquisa sobre o corpo, ela afirma que na primeira dessas linhas "[...] o corpo é visto como objeto para as ciências naturais, especialmente as ciências da vida, biologia e medicina; [...] um objeto como qualquer outro" (GROSZ, 2000, p. 57), enfatizando a necessidade de se superarem tais concepções.

Ao lançar-nos, através da personagem D. Anna Joaquina, um fio que nos conduz às narrativas do espaço urbano, Arriete Vilela introduz em seu texto a dura realidade dos "pardaizinhos". As aquarelas dessa personagem abrem caminho para que entrem em cena meninos e meninas de rua cujas "infâncias trapaceadas" escancaram as portas do espaço urbano com suas mazelas. É assim que, ao pintar com palavras a infância desamparada, triste e doída dessas personagens, a narrativa faz-se "[...] guieira de carroças fúnebres que levam meninos e meninas impunemente assassinados, enforcados, envenenados, estuprados, atropelados, queimados, afogados, mutilados" (VILELA, 2005, p. 95). Tais imagens já apontam as violências e os desrespeitos sofridos por essas crianças cujos corpos sofrem, nesse espaço heterotópico, um gradativo processo de reificação. Essa redução do corpo ao status de objeto dá-se de forma violenta através de abusos/relações sexuais que evidenciam a construção/configuração do corpo como objeto de satisfação sexual para o outro.

Num primeiro momento, essa visão do corpo é construída entre os próprios meninos e meninas de um mesmo grupo em situações nas quais os maiores abusam sexualmente dos corpos dos menores, vendo-os como objetos, ao alcance da mão, "disponíveis" para a satisfação de seus desejos:

Amendoim, 8 anos: livrou-se dos jornais com que se cobrira durante a madrugada. Seguiu na dire- 
ção do mar. Seu corpo pedia banho. Queria o sol na pele.

$[\ldots]$

Ao contato da água salgada, seu pênis ardeu. Olhou-o e então se lembrou: no meio da madrugada, sentira frio e se encostara, naturalmente, no rapazinho que dormia ao seu lado, sobre jornais. Sentindo-se aquecido, adormecera. Um tempo depois, os braços levemente imobilizados pelas mãos do colega.

- Fique quieto, é só um pouco.

$[\ldots]$

- Se gritar, os outros vão querer também.

A boca do rapazinho fazia movimentos rápidos no seu pênis. (VILELA, 2005, p. 99-100)

A violência, aqui, acontece entre meninos do mesmo grupo e é considerada uma prática comum entre eles. Para comprovar isso, basta atentar para a ameaça que o rapazinho faz a Amendoim: "se gritar, os outros vão querer também". O menino não grita, pois sabe que de parte alguma lhe chegará socorro e tem consciência da verdade da ameaça. Achando comum esse tipo de violência, os outros meninos também o violentariam se acordassem. Vemos se desenrolar, então, a redução do corpo de Amendoim ao status de objeto de prazer para meninos de seu próprio grupo. É importante observar, nesse contexto, que essa redução está diretamente ligada ao espaço marginal que essas crianças ocupam. Vivendo nas ruas, às margens das instituições sociais, elas têm todos os seus direitos primários suprimidos: falta-lhes o acesso à escola, à moradia, o amparo da família. Sem dignidade e/ou cidadania elas se tornam vítimas dessa condição marginal que se reflete no modo como seus corpos são lidos socialmente. Assim, os próprios meninos não reconhecem em si mesmos, ou nos outros, seres humanos que devem ser respeitados.

Os corpos dessas crianças, relegados ao espaço da margem, também são vistos/buscados como objetos de prazer por adultos em diferentes situações:

Petacho, 7 anos: logo cedo, sentava-se no batente da casa de Penha, à espera do pão e do caneco de café. $[\ldots]$ 
Uma noite, quando vagava pelo bairro, o menino parou no vão da porta de uma hospedaria. [...] então chegou um homem, parou diante de Petacho e o olhou fixamente. Intuitivo, o menino recuou [...]

- Tá com medo de mim, filho de uma quenga?

O menino nem podia responder, $[\ldots]$ apavorado como estava diante daquele homem de aparência bruta, todo molhado, feio, que praticamente o arrastou até um dos quartinhos do fundo e o seviciou. Depois o homem urinou sobre a cabeça de Petacho e o expulsou do quartinho [...]. (Ibidem, p. 177-178)

Ou ainda:

Cocada, 11 anos. Assume-se homossexual, mesmo quando ninguém insinua ou pergunta. Estava tendo um caso com João, 27 anos, motorista de Madame [...].

Às vezes, quando o carro de Madame deslizava pela orla, o motorista olhava discretamente para o canto do mar. Ele sabia que Cocada estava por ali $[\ldots]$ à espera $[\ldots]$ de um programa sexual. Cocada fazia sexo oral no motorista [...]

Depois o motorista largava Cocada em qualquer ponto. Pagava-lhe o que fora combinado desde o primeiro encontro: uma fatia de quebra-queixo. (Ibidem, p. 173-174)

Considerados objetos de prazer também para adultos, o uso/abuso dos corpos desses meninos dá-se, nos casos apresentados, de formas diferentes. Em ambos os casos, no entanto, percebemos como a atividade sexual é uma prática carregada de valor simbólico que não escapa dos sistemas de poder dos quais falávamos há pouco. No primeiro fragmento, o corpo de Petacho, um menino de 7 anos, é seviciado por um "homem de aparência bruta" que, depois de violentar a criança fisicamente, o faz também de forma simbólica, urinando-lhe na cabeça. A relação de poder que constitui a atividade sexual é exercida aqui negativamente de duas formas. Em primeiro lugar, deparamo-nos com a construção da imagem de um corpo reificado: o adulto violenta o corpo da criança, vendo nele 
um objeto que pode ser utilizado para satisfazer as suas vontades sexuais. Assim ele se apropria do corpo do menino e para marcar simbolicamente essa posse urina-lhe a cabeça. A segunda forma de redução dá-se através do rebaixamento do corpo do menino. Depois de usado como objeto de prazer, o corpo de Petacho é descartado e rebaixado à condição de excremento.

Já com Cocada, a reificação acontece em dois estágios diferentes, sendo operada pelo próprio menino. Num primeiro momento, ele constrói a imagem do próprio corpo como instrumento de prazer para o outro. A consciência disso o faz sair à cata de programas sexuais. A segunda forma de reificação é ainda um desdobramento dessa primeira: o menino faz de seu corpo, usado como objeto de prazer, uma mercadoria negociada por qualquer moeda. Aqui, o menino detém negativamente o poder sobre seu próprio corpo. Dispondo dele conforme sua própria vontade, Cocada o reduz à condição de objeto de prazer para o motorista com quem se relaciona; além disso, seu corpo aparece como uma mercadoria e é o próprio menino quem estabelece o preço da venda: "uma fatia de quebra-queixo".

Além dessas construções que mostram a redução do corpo desses meninos à categoria de objetos de prazer, vemos instaurar-se outra forma mais sutil de reificação quando atentamos para o modo como os corpos dessas crianças são tratados nos laudos / exames nos quais eles aparecem. A crueza de tais laudos evidencia essa forma de reificação, como prcebemos na seguinte fala da narradora:

[...] repetia a expressão constante do laudo de exame de corpo de delito, que ela carrega na bolsa, como 'ato libidinoso' e 'fissura na mucosa superior direita do ânus' [...] (p.178)

A noite, ressoava na minha cabeça, perturbando-me o sono, a linguagem crua dos exames tanatoscópicos: estado de rigidez cadavérica ausente; [...] lesão arredondada de bordas equimóticas e invertidas na região temporal esquerda, compatível com lesão de projétil de arma de fogo (disparo à distância) [...] 
'Findo o exame tanatoscópico, o corpo foi recomposto e posteriormente liberado para sepultamento'. (Ibidem, p.192)

Evidência das violências das quais essas crianças são vítimas, esses exames, com sua "linguagem crua", denunciam também o modo como esses corpos, em sua posição duplamente marginal, são tratados pelas ciências da vida, nesse caso a medicina: objetos com os quais não se precisa ter o mínimo "tato", respeito, eles são examinados e decompostos sem nenhum tipo de amparo a dor dessas crianças quando vivas, ou sem nenhum tipo de respeito, quando mortas.

A inserção desses exames, com sua "linguagem crua", no corpo da narrativa, torna ainda mais evidente as violências das quais essas crianças são vítimas. Trazer essa dura realidade social para o espaço literário reforça o componente de contestação que pode caracterizar a literatura. Denunciando os maus tratos que essas crianças sofrem, a dureza com que essa triste realidade chega aos nossos olhos, via texto literário, leva-nos a voltar nossa atenção para as crianças de rua que encontramos no nosso dia-a-dia, já que fora do espaço ficcional, a cidade está povoada de "pardaizinhos".

Assim, o texto literário desempenha o papel de elemento contestador das injustiças com as quais nos deparamos ordinariamente. Ao inserir laudos médicos na construção dessa narrativa, Arriete Vilela acentua ainda mais o caráter híbrido e fragmentário dessa obra e, principalmente, chama a atenção do/a leitor/leitra para as violências das quais essas crianças são vítimas. Verdadeiros retratos dos abusos e violências que elas sofrem, esses exames inquietam a narradora-escritora a ponto de chocá-la, tirando-lhe o sono. Denunciando as mazelas que as crianças de rua nessa obra, literalmente, sofrem na pele, tais laudos direcionam o olhar dos/as leitores/as para as crianças que estão à sua volta nos espaços urbanos, talvez na tentativa de impulsionálos/as a tomar uma atitude em relação a tais injustiças.

É importante enfatizar que essas violências fazem 
parte do processo de construção dos corpos dos meninos de rua, nessa obra, como objetos de prazer e elas estão diretamente relacionadas ao espaço que essas crianças ocupam. Espaço este que é pensado como um marcador de posição social, sendo, assim, considerado a partir da rede de relações/posicionamentos que essas crianças estabelecem entre si e com os adultos com os quais se deparam. Assim, as construções que temos de seus corpos, reduzidos à condição de objetos de prazer, estão diretamente relacionadas às posições marginais que essas crianças ocupam $^{7}$. Voltar nossa atenção para as diversas formas de reificação das quais os corpos dos meninos e meninas de rua são vítimas no espaço heterotópico da cidade na obra estudada possibilita deflagrar as construções socioculturais que estão por trás desse processo e que são responsáveis pela submissão /marginalização de mulheres e crianças.
${ }^{7} \mathrm{~A}$ pesquisa em andamento, à qual nos referimos acima, busca também observar configurações do corpo como um espaço de resistência (BRANDĀO, 2005, p. 99-121) no qual se inscreve a sua utilização como um instrumento de luta contra a submissão da mulher, seja a padrões de beleza ou a interditos culturais que releguem a sexualidade, por exemplo, ao espaço da marginalidade 


\section{Referências}

AUGÉ, Marc. Não-lugares. introdução a uma antropologia da supermodernidade. Tradução Maria Lúcia Pereira. Campinas, São Paulo: Papirus, 1994.

BACHELARD, Gaston. A dialética do interior e do exterior.

In: - A poética do espaço. Tradução de Antonio de Pádua Danesi. São Paulo: Martins Fontes, 1989.

BARBIERI, Teresita de. Sobre a categoria gênero: uma introdução teórico-metodológica. Tradução Antonia Lewinsky. S.O.S CORPO: Recife, 1993.

BELLEI, Sérgio Luiz Prado. Uma cultura na fronteira. In: . Monstros, índios e canibais: ensaios de crítica literária e cultural. Florianópolis: Insular, 2000, p.144-69. BRANDÃO, Izabel (org.). O corpo em revista: olhares interdisciplinares. Maceió: Edufal, 2005.

. Arriete Vilela encontra o fio de sua narrativa:

escritora de Marechal Deodoro lança o romance Lãs ao vento. In: Tribuna de Alagoas. Caderno arte e cultura. Maceió: domingo, 23/11/2005, p.5.

CANCLINI, Nestor Garcia. Culturas híbridas. 2. ed. São Paulo: EDUSP, 1998.

CANDIDO, Antônio. Literatura e sociedade: estudos de teoria e história literária. 7. ed. são Paulo: Editora Nacional, 1985.

. O discurso e a cidade. São Paulo: Duas Cidades, 1993.

CAVALCANTI, Ildney. "YOU'VE BEEN FRAMED": O corpo da mulher nas distopias feministas. In: BRANDÃO, Izabel (org.). O corpo em revista: olhares interdisciplinares. Maceió: Edufal, 2005. p. 83-98.

FOUCAULT, Michel. Outros espaços. In: MOTTA, Manoel Barros da. (org.). Estética: literatura e pintura, música e cinema. Tradução Inês Autran Dourado Barbosa. Rio de Janeiro: Forense Universitária, 2001. P. 411-22.

GIASSONE, Ana Cláudia. São Miguel e o dragão. Cidade e violência em "O matador", de Patrícia Melo. In: LOBO, Luiza 
\& FARIA, Márcia Gonçalves S. (org.). A poética das cidades. Rio de Janeiro: Relume Dumará, 1999.

GROSZ, Elizabeth. Corpos Reconfigurados. Cadernos Pagu (14) 2000: 45-86.

HUTCHEON, Linda. Poética do Pós-Modernismo: história, teoria, ficção. Tradução Ricardo Cruz. Rio de Janeiro: Imago, 1991.

KING, Ynestra. Curando as feridas: feminismo, ecologia e dualismo natureza/cultura. In: JAGGAR, Alison M. \& BORDO, Susan. Gênero, corpo, conhecimento. Rio de Janeiro: Rosa dos tempos, 1997. p.126-54.

NICHOLSON, Linda. Interpretando o gênero. In: Revista estudos feministas. Florianópolis, v.8, n.2. p. 9-41, 2000.

PORTER, Roy. A história do corpo. In: BURKE, Peter (org.). A escrita da história: novas perspectivas. Trad. Magda Lopes. São Paulo: UNESP, 1992, p. 291-326.

SCOTT, Joan. Gênero: uma categoria útil de análise histórica. In: Educação e realidade. Porto Alegre, 16 (2): 5-22, jul/dez 1990.

VILELA, Arriete. Lãs ao vento. Rio de Janeiro: Gryphus, 2005.

WOOLF, Virginia. Um teto todo seu. Tradução Vera Ribeiro. Rio de Janeiro: Nova Fronteira, 1985.

ZILBERMAN, Regina. A literatura infantil na escola. 11. ed.

São Paulo: Global, 2003. 